\title{
Limiting antipsychotic drugs in dementia
}

\section{Stephen Macfarlane \\ Head of Clinical \\ Governance ${ }^{1,2}$ \\ Colm Cunningham \\ Director ${ }^{1}$ \\ Associate professor ${ }^{3}$ \\ 1 Dementia Centre, HammondCare, Sydney \\ 2 Faculty of Medicine and Health Sciences, Monash University, Clayton, Victoria \\ ${ }^{3}$ School of Public Health and Community Medicine, University of New South Wales, Sydney}

\section{Keywords}

antipsychotic drugs, behavioural symptoms, dementia, deprescribing, psychotropic drugs, risperidone

Aust Prescr 2020;44:8-11 https://doi.org/10.18773/ austprescr.2020.078

\section{SUMMARY}

Most patients with dementia have behavioural and psychological symptoms. The first-line treatments for these symptoms are not drugs, but behavioural and psychological interventions.

Antipsychotic drugs are widely prescribed for people living with dementia. This is despite a high adverse effect burden and limited evidence of efficacy.

Most behavioural and psychological symptoms will subside spontaneously within six months. Trials of deprescribing are therefore recommended.

Behaviours should be seen as symptoms that have an underlying cause. Treatment should target these causes, rather than the resultant behaviours.

\section{Introduction}

Older people are prescribed psychotropic drugs at a rate that dwarfs that of younger cohorts (Fig. 1).,2 Much of this prescribing occurs in residential care settings. The prevalence of antipsychotic use may be up to $44 \%$ in this population. ${ }^{3} \mathrm{~A}$ large proportion of antipsychotic prescribing occurs in the three months before someone enters aged care. It then increases markedly in the three months after admission. ${ }^{4}$ These drugs are often prescribed for the management of the behavioural and psychological symptoms of dementia. This is despite a lack of efficacy and high rates of adverse effects. ${ }^{5}$ It has been estimated that only $10 \%$ of psychotropic prescribing for those living with dementia is appropriate. ${ }^{6}$

\section{Antipsychotic effectiveness}

Many behaviours that can occur in dementia are unlikely to respond to pharmacotherapy at all. For example, there is no drug treatment for wandering, or calling out. A drug cannot be expected to modify behaviours such as shadowing staff, exit-seeking, disrobing or inappropriate voiding. In such cases, the only means by which an antipsychotic may have efficacy is by sedating the person to the point where they are no longer able to engage in such behaviours. This constitutes chemical restraint.

Placebo response rates in randomised controlled trials of antipsychotics for behavioural and psychological symptoms of dementia are high. This reflects the high rate of spontaneous remission of all these types of symptoms within three months. ${ }^{7}$ When an antipsychotic has been prescribed and a behaviour subsequently resolves, it may be tempting to conclude that this is because of the drug, however the behaviour may well have settled without the drug.
The behaviours for which antipsychotics may have some benefit are limited to psychosis, agitation and aggression. However, apart from psychosis, the mechanism of action is unclear, so the effects may also represent non-specific sedation.

In Australia, risperidone is the only antipsychotic approved for the treatment of behavioural and psychological symptoms of dementia. However, there are data that other antipsychotics are frequently prescribed off label for the behavioural and psychological symptoms of dementia. ${ }^{8}$ The Pharmaceutical Benefits Scheme restricts the use of risperidone to behavioural symptoms characterised by psychosis and aggression in those with Alzheimer's disease, for a 12-week period, and only after nonpharmacological interventions have failed. While there is evidence that risperidone can benefit the specific behavioural and psychological symptoms of agitation and aggression, the effect sizes are small. ${ }^{9}$

The adverse effect burden of antipsychotic drugs is significant and includes falls, sedation, extrapyramidal adverse effects and death. These problems are often treatment-emergent and related not only to dose, but duration of exposure, underlining the need for frequent monitoring for adverse effects. The limited efficacy of antipsychotics, combined with their poor tolerability and safety profile, makes the obtaining of consent vital before starting any treatment. An assessment of an individual's capacity to refuse treatment must always be made before seeking proxy consent from an authorised decision maker.

\section{Deprescribing}

A deprescribing plan should be provided when starting an antipsychotic drug in a patient with dementia. If an antipsychotic has been prescribed and the symptoms settle, a trial of deprescribing is warranted. Figure 2 


\section{Fig. 1 Proportion of population accessing subsidised antipsychotic drugs in $2011^{2}$}

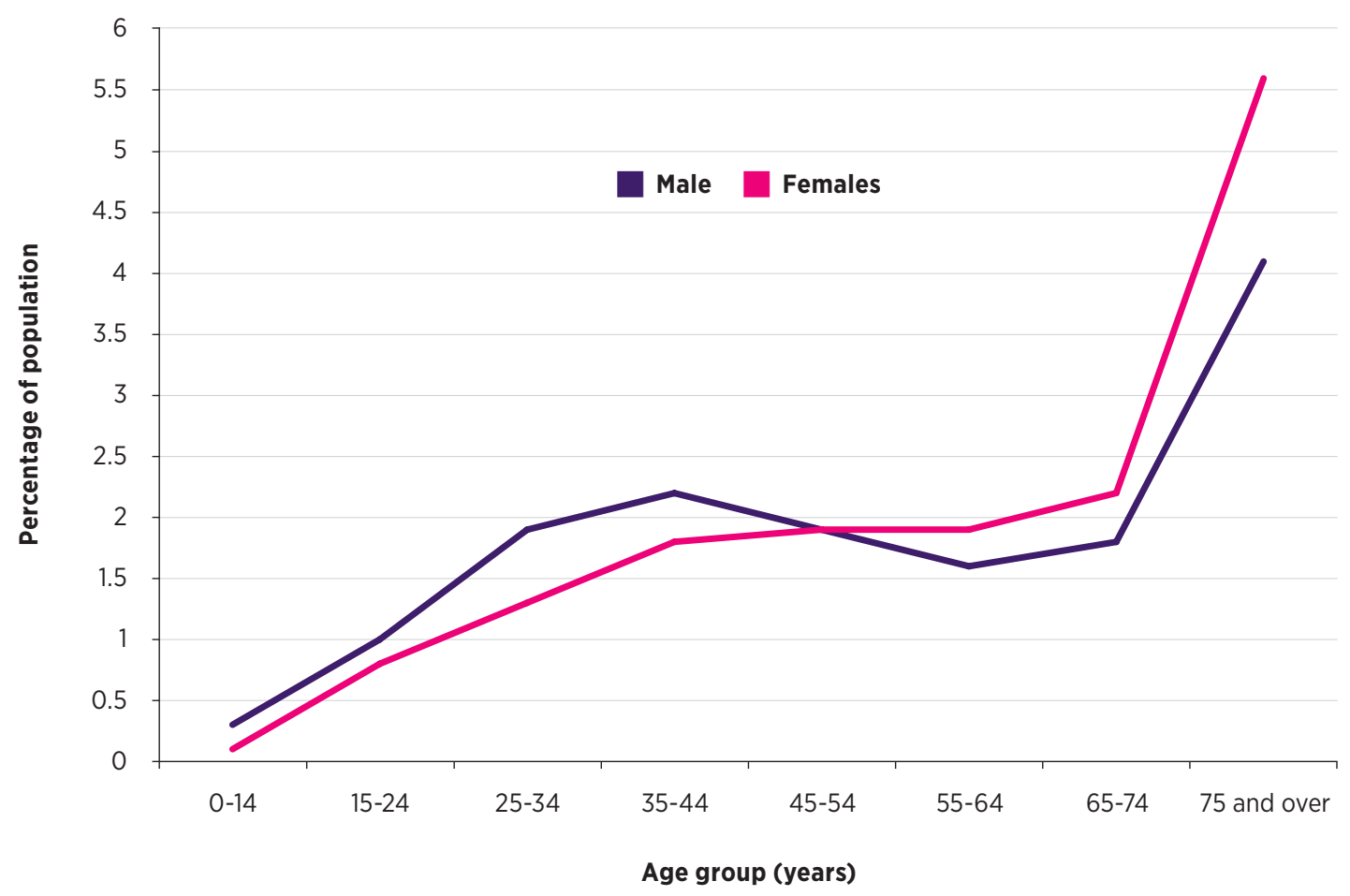

shows an algorithm as to how deprescribing might be approached. ${ }^{10}$ It is important to involve other members of the multidisciplinary team such as nurses and a pharmacist in the development of a deprescribing plan. Deprescribing provides an ideal opportunity to try specific non-drug strategies for any behaviours that might re-emerge as the drug is withdrawn.

\section{Assessing the patient}

It is important to identify what may be causing the behavioural and psychological symptoms in someone with dementia. Agitation and aggression are symptoms, not diagnoses. Just because a drug may have efficacy in treating agitation does not mean that the drug is indicated in response to the symptom. The key to developing effective non-pharmacological interventions is an accurate assessment of the cause of the behavioural symptoms. Appropriate management cannot occur in the absence of adequate assessment. Common causes of symptoms include unrecognised or undertreated pain, depression, and delirium. Expert consensus for the pharmacotherapy of behavioural and psychological symptoms of dementia emphasises trials of analgesia and antidepressants before considering antipsychotic use." If an antipsychotic is going to be used, the need for continuing analgesics and antidepressants should be reviewed.

\section{Multidisciplinary approach}

The Commonwealth Government has funded free, national dementia behaviour-management services since 2007. The various state and territory-based services were united under a single provider, Dementia Support Australia, in 2016. This has a multidisciplinary workforce with expertise in the assessment and non-pharmacological management of the behavioural and psychological symptoms of dementia. It is backed by a national team of geriatricians and old-age psychiatrists. Referrals can be made via 1800699799 or online.

\section{Conclusion}

The evidence for the efficacy of antipsychotic drugs in the treatment of behavioural and psychological symptoms of dementia is unconvincing. However, the drugs cause definite harm including an increased risk of death.

The common medical causes of altered behaviour in someone with dementia should be identified. More detailed evaluation and the subsequent development of individualised behaviour-management plans can involve referral to a multidisciplinary team with experience in the area. $\varangle$ 


\section{Fig. 2 Antipsychotic deprescribing algorithm ${ }^{10}$}

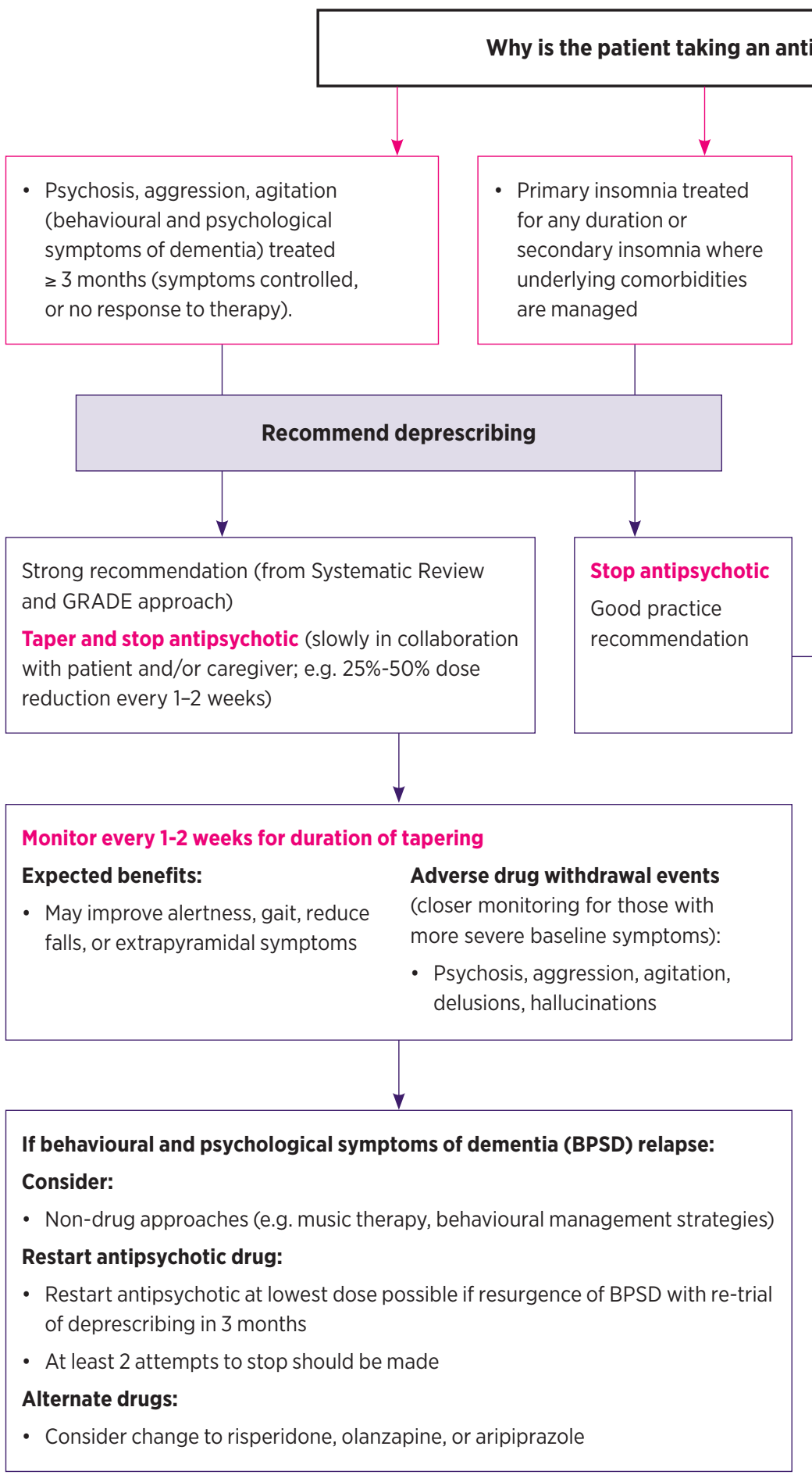

\section{$\downarrow$}

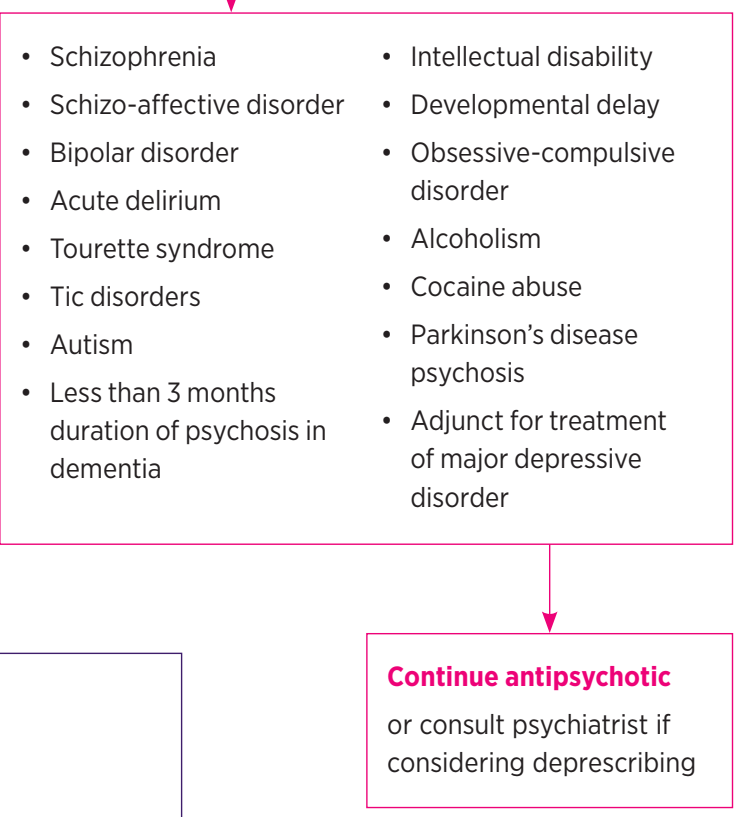

Monitor every 1-2 weeks for duration of tapering

Adverse drug withdrawal events (closer monitoring for those with (ulusions, hallucinations

\section{(c) Use freely, with cred
without permission.}

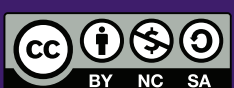

This work is licensed under a Creative Commons Attribution-NonCommercialShareAlike 4.0 International License. Contact deprescribing@bruyere.org or visit deprescribing.org for more information.

Bjerre LM, Farrell B, Hogel M, Graham L, Lemay G, McCarthy L, et al. Deprescribing antipsychotics for behavioural and psychological symptoms of dementia and insomnia: Evidence-based clinical practice guideline. Can Fam Physician 2018;64:17-27 (Eng), e1-e12 (Fr)

\section{If insomnia relapses: \\ Consider}

- Minimise use of substances that worsen insomnia (e.g. caffeine, alcohol)

- Non-drug behavioural approaches

\section{Alternate drugs}

- Other medications have been used to manage insomnia. Assessment of their safety and effectiveness is beyond the scope of this deprescribing algorithm. See Antipsychotic Deprescribing Guideline for details.

\section{deprescribing.org}

\section{Bruyère do open}


Conflicts of interest: Stephen Macfarlane has received research funding from Janssen-Cilag, Eli Lilly, Eisai, Roche, Anavex Life Sciences, Prana Biotechnology, Alector, Sanofi, Pfizer, Forest, Velacor, Lundbeck, Cognition Therapeutics, Genentech. Speakers' honoraria have been provided by Eli Lilly, Janssen, Pfizer and Lundbeck. Stephen Macfarlane has served on a Scientific Advisory Board for Eli Lilly. He is an employee of

Dementia Support Australia.

\section{REFERENCES}

1. Australian Institute of Health and Welfare. Mental health services in Australia. Medicare-subsidised mental healthspecific services. Figure MBS.2. Proportion of population receiving Medicare-subsidised mental health-specific services, by demographic group, 2018-19. Canberra: AlHW; 2020 Oct 13. www.aihw.gov.au/reports/mental-healthservices/mental-health-services-in-australia/reportcontents/medicare-subsidised-mental-health-specificservices [cited 2021 Jan 4]

2. Australian Bureau of Statistics. Patterns of use of mental health services and prescription medications: analysis of patterns of use of MBS subsidised mental health-related services and PBS subsidised mental health-related medications in 2011. Canberra: Australian Bureau of Statistics; 2016 Mar 24. https://www.abs.gov.au/statistics/health/ mental-health/patterns-use-mental-health-services-andprescription-medications/latest-release [cited 2021 Jan 4]

3. Westaway K, Sluggett J, Alderman C, Moffat A, Procter N, Roughead $\mathrm{E}$. The extent of antipsychotic use in Australian residential aged care facilities and interventions shown to be effective in reducing antipsychotic use: a literature review. Dementia 2020;19:1189-202. https://doi.org/10.1177/ 1471301218795792

4. Harrison SL, Sluggett JK, Lang C, Whitehead C, Crotty M, Corlis $\mathrm{M}$, et al. The dispensing of psychotropic medicines to older people before and after they enter residential aged care. Med J Aust 2020;212:309-13. https://doi.org/10.5694/ mja2.50501

5. Maher AR, Maglione M, Bagley S, Suttorp M, Hu JH, Ewing B, et al. Efficacy and comparative effectiveness of atypical antipsychotic medications for off-label uses in adults: a systematic review and meta-analysis. JAMA 2011;306:1359-69. https://doi.org/10.1001/jama.2011.1360
6. van der Spek K, Gerritsen DL, Smalbrugge M, Nelissen-Vrancken $\mathrm{MH}$, Wetzels RB, Smeets $\mathrm{CH}$, et al. Only $10 \%$ of the psychotropic drug use for neuropsychiatric symptoms in patients with dementia is fully appropriate. The PROPER I-study. Int Psychogeriatr 2016;28:1589-95. https://doi.org/10.1017/S104161021600082X

7. van der Linde RM, Dening T, Stephan BC, Prina AM, Evans E, Brayne C. Longitudinal course of behavioural and psychological symptoms of dementia: systematic review. Br J Psychiatry 2016;209:366-77. https://doi.org/10.1192/ bjp.bp.114.148403

8. Pharmaceutical Benefits Advisory Committee Drug Utilisation Sub-Committee. DUSC review on the utilisation of antipsychotics - August 2013. Public Summary Document. Canberra: Australian Government Department of Health, PBS; 2013. https://www.pbs.gov.au/pbs/industry/listing/ elements/pbac-meetings/psd/2013-08/antipsychotics [cited 2021 Jan 4]

9. Dyer SM, Harrison SL, Laver K, Whitehead C, Crotty M. An overview of systematic reviews of pharmacological and non-pharmacological interventions for the treatment of behavioral and psychological symptoms of dementia. Int Psychogeriatr 2018;30:295-309. https://doi.org/10.1017/ S1041610217002344

10. Bjerre LM, Farrell B, Hogel M, Graham L, Lemay G, McCarthy L, et al. Deprescribing antipsychotics for behavioural and psychological symptoms of dementia and insomnia: evidence-based clinical practice guideline. Can Fam Physician 2018;64:17-27.

11. Kales HC, Lyketsos CG, Miller EM, Ballard C. Management of behavioral and psychological symptoms in people with Alzheimer's disease: an international Delphi consensus. Int Psychogeriatr 2019;31:83-90. https://doi.org/10.1017/ S1041610218000534

\section{FURTHER READING}

Dementia and psychotropic medicines: understanding the options available to manage changed behaviour in this complex condition. Sydney: NPS MedicineWise; 2020. https://www.nps.org.au/ professionals/antipsychotic-medicines [cited 2021 Jan 4]
Risperidone: revised PBS restrictions for behavioural and psychological symptoms of dementia. RADAR 2020 Mar 19 https://www.nps.org.au/radar/articles/risperidone-revised-pbsrestrictions-for-behavioural-and-psychological-symptoms-ofdementia [cited 2021 Jan 4] 